\title{
VIRULENCE FACTORS AND DRUG RESISTANCE OF GASTROINTESTINAL ESCHERICHIA COLI ISOLATED FROM DIFFERENT ANIMALS
}

\author{
A. P. NANDA ${ }^{1}$ AND S. K. NAYAK ${ }^{1 *}$ \\ ${ }^{1}$ Department of Biotechnology, North Orissa University, Baripada, Mayurbhanj-757 003, Odisha, India
}

\begin{abstract}
Escherichia coli is one of the natural colonizers in the gastrointestinal tract of several animals ranging from terrestrial to aquatic origin. Nowadays virulence attributes of $E$. coli along with antibiotic resistance pattern is a global crisis. Therefore, it is of utmost importance to monitor the possible virulence characteristics as well as the antibiotic-resistant pattern among the $E$. coli isolates residing in the gastrointestinal tract of different animals. In this study, a total of $42 \mathrm{E}$. coli isolates from the gastrointestinal tract of different species like pig, broiler, chicken, fish and goat, as well as from the stool samples of human, were studied for their virulence attributes and antibiotic resistance. Based on the various virulence traits like biofilm-forming, congo red binding, proteolytic, haemolytic, and haemagglutinating activity, this study indicated that $80 \%$ of isolates possessed putative factors associated with pathogenicity. Further, these isolates were found to be the extended-spectrum $\beta$-lactamase producer and resistant to at least 5 antibiotics, which is a matter of concern since the possibility of horizontal transfer and health implications in the host as well as to human can't be ruled out.
\end{abstract}

Key words: Antibiotics, Biofilm, Congo red, Escherichia coli, Virulence

\section{INTRODUCTION}

Escherichia coli, a rod-shaped, Gram-negative, facultative anaerobic coliform bacterium of gamma proteobacterium of Enterobactericeae, is a natural colonizer in the gastrointestinal tract of warm-blooded animals. E. coli are mostly commensal gut microbiota. Despite this, it is associated with several complications in different animals and humans. Contamination of water and food with faecal bacteria remains a common and persistent problem leading to outbreaks of food- and water-borne illness, impacting public health. E. coli isolates can be enteroinvasive, enterotoxigenic, enteroadherent, enteropathogenic, enterohemorrhagic and diffusely adherent. Shiga- toxigenic E. coli can cause severe complications like bloody diarrhea, hemorrhagic colitis, thrombocytopenia, hemolytic anemia, lethal hemolytic uremic syndrome, and acute renal failure (Jafari et al., 2012; de Mello Santos et al., 2020). Virulence in $E$. coli isolates is often multifactorial with several virulence factors associated with biofilm production, protease activity, gelatinase activity mannose resistant haemagglutination, cell surface hydrophobicity, and serum resistance, etc (Shetty et al., 2014; Bhrugubalda et al., 2016). Therefore it is utmost importance to determine the factor responsible for diseases for adopting suitable prophylaxis measures.

\footnotetext{
*Corresponding Author
} 
While antibiotic therapy remains the main prophylaxis measure, in the present era of everincreasing antibiotic resistance is a matter of deep concern. Inappropriate use of antibiotics is the main reason of the emergence and dissemination of resistance genes in animals, humans and the environment (Bryce et al., 2016; Sasikala et al., 2019; Odongo et al., 2020). Over the years, the resistance to antibiotics like cephalosporin among members of Enterobacteriaceae has increased mainly due to the spreading of Extended-spectrum $\beta$-lactamase (ESBL). Further, ESBL producers carry genes for resistance to other antimicrobial agents due to their presence in the same plasmid of ESBL (Rawat and Nair, 2010), and the incidence of ESBL producing $E$. coli strains have been increasing, which becomes a limiting factor for therapeutic applications (Mathur et al., 2002).

Nowadays virulent attributes along with antibiotic resistance of $E$. coli is a major concern for researchers (Thomson and Moland, 2000; Bhrugubalda et al., 2016; Mohammadi-Sardo et al., 2017). Several characters such as biofilmforming, congo red binding potency, proteolytic activity (Sheikh et al., 2001; Shetty et al., 2014) along with haemagglutination, haemolysin and haemolytic activities are attributed to the virulence of this bacterium. It is, therefore, of utmost importance to monitor the possible virulence characteristics as well as antibiotic resistance pattern among the $E$. coli isolates from the gastrointestinal tract of different animals, which in turn will help to know the prevalence of various virulent traits as well as the antibioticresistant pattern among the normal microbiota of animals. So that adequate prophylaxis measures can be taken to minimise and control the pathogens. Therefore, the present investigation was carried out to study the virulence attributes, antibiotic resistance pattern, and ESBL producing ability of $E$. coli isolates obtained from the gastrointestinal tract of various animals.

\section{MATERIALS AND METHODS}

Sample collection: All the experiments were conducted following standard procedures and in compliance with the ethical guideline and clearance of North Orissa University (NOU), Odisha, India. The gastrointestinal tract of different animals like pig (Sus domesticus), goat (Capra aegagrus hircus), broiler (Gallus gallus), fish (Rohu, Labeo rohita), chicken (Gallus gallus domesticus) were aseptically collected and processed at the Department of Biotechnology, NOU, Odisha, India for isolation of $E$. coli. Besides, stool samples from human were also processed for isolation of $E$. coli. The isolation of gastrointestinal tract from apparently healthy animals and birds with no previous history of drugs/antibiotics treatment was conducted under the supervision of a qualified Veterinarian. The isolation of gut from the animals and birds was conducted with the approval of the institutional animal ethical committee.

Isolation and identification of $\boldsymbol{E}$. coli isolates: The gastrointestinal tract (GI) of different animals were processed for isolation of $E$. coli as per standard microbiological methods (Cowan and Steel, 1975). Briefly, the gut content was removed by squeezing the tract followed by repeated washing with phosphate-buffered saline (PBS, pH 7.2). The GI tract was then homogenized with PBS with the help of mortar and pestle. Then the suspension was diluted and plated onto Mac-Conkey agar (Hi-Media, India) plates and incubated at $37^{\circ} \mathrm{C}$ overnight. After incubation, lactose fermenting pink colonies were picked and streaked on Eosin methylene blue (EMB) agar (Hi-Media, India) plates and incubated at $37^{\circ} \mathrm{C}$ for overnight. After incubation large, blue-black colonies with a green metallic sheen were picked from EMB plates and again sub-cultured onto the same media for obtaining pure culture. Finally, the individual black centered colony was maintained in slants. Similarly, stool samples were also processed for isolation of E. coli. After isolation, all isolates were processed through a series of biochemical 
tests and isolates were identified and characterised based on the colony morphology and biochemical characteristics (Cowan and Steele, 1975; Cruickshank et al., 1975).

Virulent attributes of the $\boldsymbol{E}$. coli: The biofilmforming ability of $E$. coli isolates was done as per the procedure of Christensen et al. (1985). Briefly, E. coli isolates were grown in nutrient broth at $37^{\circ} \mathrm{C}$ for $18-24 \mathrm{hrs}$. The cultured broth was decanted and the tubes were poured with $1 \%$ crystal violet solution for $1 \mathrm{hr}$. The test tubes were then washed with distilled water after gently removing the crystal violet solution. Finally, $2 \mathrm{~mL}$ of $30 \%$ acetic acid was added and then the OD value was measured at 600 $\mathrm{nm}$. Based on OD values, the isolates were interpreted as strong positive (OD value $>1.0$ ), positive (OD value between 0.5 and 1.0) or negative (OD value $<0.5$ )

The ability of E. coli isolates to bind congo red dye was carried out in congo red agar plate as per the procedure of Berkhoff and Vinal (1986) and the proteolytic activity of the isolates was tested in skim milk agar plates as per the method of Abd Samad et al. (2017). Similarly, the haemolytic activity of the $E$. coli isolates was done by using $5 \%$ blood agar plates of species like human, fish, pig, broiler, goat and chicken as per the protocol of Roy et al. (2006).

\section{Haemagglutinating and haemolysin activity:} The haemagglutinating activity of the E. coli isolates was tested against red blood cells (RBCs) from various sources like human, fish, goat and chicken as per Shetty et al. (2014) with slight modifications. Briefly, the assay was conducted in ' $U$ ' shaped microtitre plates by serial two-fold dilution of $50 \mu \mathrm{L}$ bacterial sample with PBS (pH 7.2). Then $50 \mu \mathrm{L}$ of freshly prepared 1\% RBC suspension of individual species were separately added to each well. The plates were kept $28-30^{\circ} \mathrm{C}$ for 2 hrs. After incubation, the plates were observed for agglutination of erythrocytes. The haemagglutination titre was calculated as the reciprocal of the highest dilution of bacteria showing complete agglutination of RBCs. The haemolysin activity was conducted in a similar manner and incubation was done overnight at $4^{\circ} \mathrm{C}$. After incubation, haemolysis of erythrocytes was recorded and the haemolysin titre was calculated in a similar manner.

Antibiotic resistance pattern study: The antibiotics resistance pattern of $E$. coli isolates against 20 different antibiotics such as ampicillin $(10 \mathrm{mcg})$, amoxicillin $(10 \mathrm{mcg})$, ceftazidime (30 mcg), cefoperazone $(75 \mathrm{mcg})$, cefpodoxime $(30 \mathrm{mcg})$, cefepime $(30 \mathrm{mcg})$, clotrimazole $(10 \mathrm{mcg})$, cefazolin $(30 \mathrm{mcg})$, cefotaxime (30 mcg), cotrimaxozole $(25 \mathrm{mcg})$, ceftriaxone $(30 \mathrm{mcg})$, chloramphenicol $(30$ $\mathrm{mcg}$ ), meropenem (10 mcg), moxifloxacin (5 $\mathrm{mcg}$ ), nystatin (100 units), nitrofurantoin (300 $\mathrm{mcg}$ ), norfloxacin (10 $\mathrm{mcg}$ ), nitrofurantoin (300 mcg), penicillin (10 units) and tetracycline (30 mcg) (HiMedia, India) was performed on Mueller Hinton agar at $37^{\circ} \mathrm{C}$ for $24 \mathrm{hrs}$ as per standard agar-disc diffusion method (Bauer $e t$ al., 1966). The selection of antimicrobial drugs was based on their common use, availability and as per the recommendations of Clinical and Laboratory Standards Institute (CLSI). After incubation, the zone of inhibition was measured and interpreted as sensitive, resistant and intermediate sensitive as per CLSI recommendations (Clinical and Laboratory Standards Institute, 2014).

\section{Extended-spectrum beta-lactamase (ESBL)} detection assay: The ESBL screening was done by the standard disc diffusion method as described in ESBL kit (HiMedia, India) containing cefotaxim and cefotaxim with clavulinic acid. After incubation, the zone of inhibition was measured and the results were interpreted as per the manufacturer's instruction. 


\section{RESULTS}

In this study, a total of 42 isolates were purified from the GI tract of goat (10), chicken (11), broiler (12), pig (3) and fish (2). Similarly, 4 isolates were obtained from human stool samples. All the isolates were identified as $E$. coli phenotypically (Table 1).

Virulent attributes of $\boldsymbol{E}$. coli: All the $E$. coli isolates from different sources exhibited various virulent attributes like biofilm-forming, congo red binding, proteolytic and haemolytic activity. E. coli isolates exhibited variable biofilmforming ability with respect to the source of isolation (Fig. 1a). All the E. coli isolates from

Table 1. Biochemical characteristics of $E$. coli isolates $(n=42)$ from different sources

\begin{tabular}{lc}
\hline Tests/Parameters & Characteristics \\
\hline Gram reaction & - \\
Morphology & Rods \\
Motility & Motile \\
Catalase & + \\
Oxidase & - \\
Methyl red reaction & + \\
Voges-Proskauer reaction & - \\
Indole production & + \\
Citrate utilization & - \\
Oxidative/fermentative reaction & $+/$ \\
Hydrogen sulfide production & - \\
Gas from glucose & + \\
Nitrate reduction & + \\
\hline Fermentation of sugars & \\
\hline Glucose & + \\
Lactose & + \\
Sucrose & + \\
Sorbitol & + \\
Mannitol & + \\
Inositol & + \\
Mannose & - \\
Fructose & - \\
Maltose & - \\
Raffinose & - \\
Ribose & - \\
\hline
\end{tabular}

human and pig were strong biofilm formers. Similarly, $50 \%$ of the E. coli isolates from fish and pig were strong biofilm formers. On the other hand, the highest percent of non-biofilm forming isolates were from chicken $(54.55 \%)$ followed by the goat (40\%). E. coli isolates were found to possess congo red binding potency but the pattern of the binding potency varied among isolates. All the E. coli isolates from human (stool) exhibited strong congo red binding activity. The percentage of E. coli isolates from chicken, broiler and goat with strong dye-binding activity was 63.0, 57.0 and 40.0, respectively. E. coli isolates from pig and fish were positive only after $72 \mathrm{hrs}$ of incubation. However, $30 \%, 27.27 \%$ and $21.0 \%$ of the E. coli isolates from goat, chicken and broiler, respectively were congo red negative (Fig. 1b). E. coli isolates irrespective of sources exhibited proteolytic activity but their percentage varied among the source of isolation (Fig 1c). All the E. coli isolates from pig and human stool exhibited proteolytic activity. The percentage of isolates from goat, broiler chicken and fish with proteolytic activity was 77.0, 83.0, 75.0 and 50.0, respectively. E. coli isolates from all the sources except pig were haemolytic to different erythrocytes. E. coli isolates from goat were found to haemolyse all the tested erythrocytes. Highest percent of E. coli isolates (50.0) from goat haemolysed chicken erythrocytes followed by $20 \%$ of the total isolates to haemolyse both goat and fish erythrocytes (Table 2). E. coli isolates from fish were found to haemolyse the erythrocytes of human $(50 \%)$ and fish (50\%), and nonhaemolytic to broiler and goat erythrocytes. Similarly E. coli isolates from human and chicken were haemolytic to goat, broiler and fish erythrocytes, and non-haemolytic to human erythrocytes. E. coli isolates from broiler were haemolytic to the erythrocytes of human, goat and broiler erythrocytes, and non-haemolytic to fish erythrocytes. 
a)

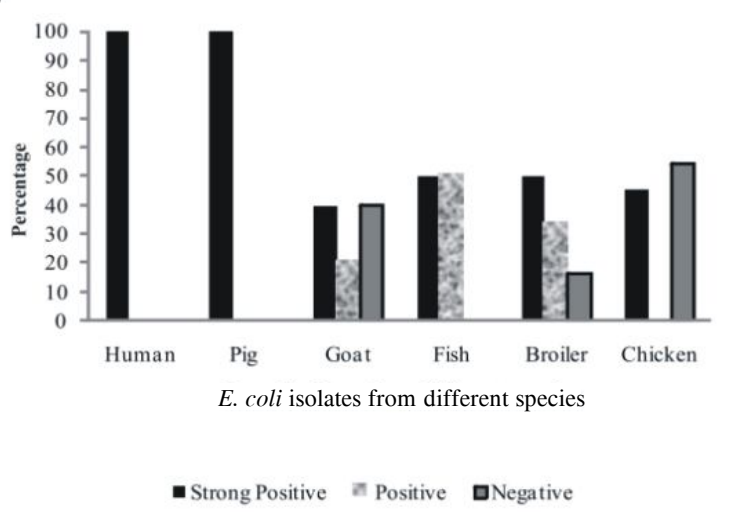

b)

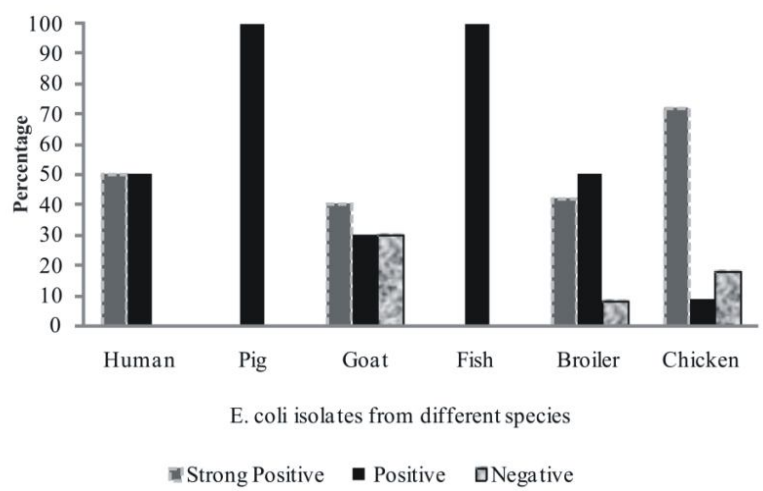

c)

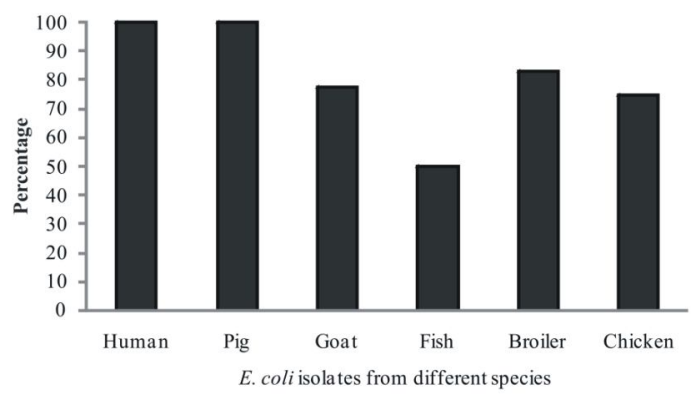

Fig. 1(a-c) Percentage of E. coli isolates from different sources showing different virulent characteristics a) Biofilm forming activity, b) Congored binding activity, c) Proteolytic activity

Table 2. Percentage of $E$. coli isolates of different sources showing haemolytic activity against homologous and heterologous erythrocytes

\begin{tabular}{lcclllll}
\hline \multirow{2}{*}{$\begin{array}{l}\text { Source of } \\
\text {. coli }\end{array}$} & $\begin{array}{c}\text { No. of } \\
\text { isolates }\end{array}$ & \multicolumn{7}{c}{ Erythrocytes of } \\
\cline { 2 - 8 } & 2 & Human & Pig & Goat & Fish & Broiler & Chicken \\
\hline Fish & 30 & 0 & 0 & 50 & 0 & 0 \\
Pig & 3 & 0 & 33.33 & 33.33 & 0 & 33.33 & 33.33 \\
Human & 4 & 0 & 0 & 50 & 50 & 75 & 0 \\
Chicken & 11 & 0 & 0 & 45.45 & 36.36 & 54.54 & 45.45 \\
Goat & 10 & 10 & 20 & 20 & 20 & 10 & 50 \\
Broiler & 12 & 50 & 0 & 66.66 & 0 & 75 & 0 \\
\hline
\end{tabular}

Haemagglutination and haemolysin titre: All the E. coli isolates were found to agglutinate erythrocytes of different species. The haemagglutinating activity of $E$. coli isolates from the pig was the least against all the tested erythrocytes. However, E. coli isolates from goat exhibited high haemagglutinating activity with geometric mean titre value of 1.31, 2.0, 1.0, 1.0 and 2.0 against erythrocytes of fish, broiler, pig, human and goat, respectively (Table 3). Similarly, all the E. coli isolates were haemolysin producers. E. coli isolates from fish, pig, broiler and human were exhibited high haemolysin titre value with the geometric mean of 6.4 against pig and human erythrocytes. The haemolysin titre of fish, pig and human isolates against goat erythrocytes was also 6.4. The geometric mean value of haemolysin titre goat isolates against the pig, human and goat erythrocytes were 5.27, 5.27 and 9.18, respectively (Table 3).

Antibiotic resistance pattern: The drug 
resistance pattern of all $E$. coli isolates was studied against 20 antibiotics. E. coli isolates from the goat were resistant to a maximum number of antibiotics followed by chicken and broiler (Table 4). E. coli isolates from human were found to be resistant to cefotaxime, ceftriaxone and chloramphenicol and only intermediate sensitive to cotrimaxozole and tetracycline.

Production of Extended-spectrum betalactamase enzyme (ESBL): $E$. coli isolates from goat, broiler, fish and human were resistant to cefotaxime (CTX). The isolates of chicken and pig were found to be intermediate sensitive and sensitive, respectively (Table 5). Similarly, isolates of pig and chicken were sensitive to cefotaxime and clavulinic acid (CEC) combination. On the other hand, fish isolates were resistant to cefotaxime and clavulinic acid combination. One isolate each from both goat and broiler also showed resistant activity against CEC. Among the tested isolates, two isolates of fish, one isolate from goat and broiler were found to be ESBL procedure.

\section{DISCUSSION}

E. coli is one of the most important zoonotic enteric pathogens and the most widely accepted indicator of faecal contamination in food and water. Virulence pattern of $E$. coli is often

Table 3. The geometric mean values of haemagglutination and haemolysin titre of the $E$. coli isolates against different erythrocytes

\begin{tabular}{lccccc|cccccc}
\hline $\begin{array}{l}\text { Source of } \\
\text { E. coli }\end{array}$ & $\begin{array}{l}\text { No. of } \\
\text { is olates }\end{array}$ & \multicolumn{4}{c|}{$\begin{array}{c}\text { Haemaglutination titre against } \\
\text { erythrocytes of }\end{array}$} & \multicolumn{4}{c}{$\begin{array}{c}\text { Haemolysin titre against } \\
\text { erythrocytes of }\end{array}$} \\
\cline { 2 - 13 } & & Fish & Broiler & Pig & Human & Goat & Fish & Broiler & Pig & Human & Goat \\
\hline Fish & 2 & 1.41 & 1.0 & 1.0 & 1.0 & 1.0 & 1.41 & 1.41 & 6.4 & 6.4 & 6.4 \\
Pig & 3 & 1.0 & 1.0 & 1.0 & 1.0 & 1.0 & 1.0 & 1.0 & 6.4 & 6.4 & 6.4 \\
Human & 4 & 1.41 & 1.0 & 1.0 & 1.41 & 1.0 & 1.41 & 1.0 & 6.4 & 1.0 & 6.4 \\
Chicken & 11 & 1.06 & 1.13 & 1.06 & 1.06 & 1.13 & 1.20 & 1.13 & 6.4 & 1.65 & 11.67 \\
Goat & 10 & 1.31 & 2.0 & 1.0 & 1.0 & 2.0 & 1.31 & 1.14 & 5.27 & 5.27 & 9.18 \\
Broiler & 12 & 1.16 & 1.36 & 1.08 & 1.36 & 1.36 & 1.16 & 1.71 & 6.4 & 6.4 & 2.25 \\
\hline
\end{tabular}

Table 4. The resistance pattern of $E$. coli isolates from different sources towards common antibiotics

\begin{tabular}{lcl}
\hline Sources & $\begin{array}{c}\text { Number of } \\
\text { isolates }\end{array}$ & \multicolumn{1}{c}{ Antibiotics } \\
\hline Broiler & 12 & $\begin{array}{l}\text { Ceftriaxone, Cefazolin, Cefotaxime, Clotrimazole, Nystatin, Penicillin, } \\
\text { Cotrimaxozole* }^{*}\end{array}$ \\
\hline Human & 4 & Cefotaxime, Cefazolin, Chloramphenicol, Ceftriaxone*, Tetracycline* $^{*}$ \\
\hline Fish & 2 & $\begin{array}{l}\text { Ceftriaxone, Cefotaxime, Cefazolin, Nystatin, Clotrimazole, Penicillin, } \\
\text { Cotrimaxozole }\end{array}$ \\
\hline Goat & 10 & $\begin{array}{l}\text { Ampicillin, Cefotaxime, Meropenem, Cefepime, Ceftazidime, } \\
\text { Cefpodoxime, Cefoperazon }\end{array}$ \\
\hline Chicken & 11 & $\begin{array}{l}\text { Cotrimaxozole, Ceftriaxone, Cefepime, Ceftazidime, Cefpodoxime, } \\
\text { Cefoperazon, Cefotaxime* }\end{array}$ \\
\hline Pig & 3 & Ceftriaxone, Cefazolin, Clotrimazole, Nystatin, Penicillin \\
\hline
\end{tabular}

"indicates "intermediate sensitive" bacteria 
Table 5. $\beta$-Lactamase producing ability of $E$. coli isolates from various sources

\begin{tabular}{lcc}
\hline $\begin{array}{l}\text { Source of } \\
\text { c coli }\end{array}$ & \multicolumn{2}{c}{ Sensitivity pattern towards } \\
\cline { 2 - 3 } & Cefotaxime & $\begin{array}{c}\text { Cefotaxime + } \\
\text { Clavulanic acid }\end{array}$ \\
\hline Goat1 & $\mathrm{R}$ & $\mathrm{S}$ \\
Goat2 & $\mathrm{R}$ & $\mathrm{R}^{*}$ \\
Broiler1 & $\mathrm{R}$ & $\mathrm{R}^{*}$ \\
Broiler2 & $\mathrm{R}$ & $\mathrm{IS}$ \\
Fish1 & $\mathrm{R}$ & $\mathrm{R}^{*}$ \\
Fish2 & $\mathrm{R}$ & $\mathrm{R}^{*}$ \\
Human1 & $\mathrm{R}$ & $\mathrm{IS}$ \\
Human2 & $\mathrm{R}$ & $\mathrm{IS}$ \\
Chicken1 & $\mathrm{IS}$ & $\mathrm{S}$ \\
Chicken2 & $\mathrm{IS}$ & $\mathrm{S}$ \\
Pig1 & $\mathrm{S}$ & $\mathrm{S}$ \\
Pig2 & $\mathrm{S}$ & $\mathrm{S}$ \\
\hline
\end{tabular}

${ }^{*}$ ESBL producing isolates; $\mathrm{S}$ - sensitive ;

IS - intermediate sensitive; $\mathrm{R}$ - resistant

multifactorial and, therefore, studies on virulence factors have very important practical implications. In the present investigation, E. coli were successfully isolated, identified and evaluated for their virulent attributes and antibiotic resistance pattern.

The congo red binding is often correlated with the pathogenicity of the organism and possibly used as a phenotypic marker to distinguish invasive and non-invasive E. coli (Panigrahy and Yushen, 1990; Sharma et al., 2007). Berkhoff and Vinal (1986) found that about half of the environmental and cloacal isolated $E$. coli was congo red positive, while Panigrahy and Yushen (1990) found that $61.9 \%$ of the E. coli were congo red positive. Similarly, about $45-47.42 \%$ of the entero-invasive $E$. coli were able to bind congo red (Sharma et al., 2007). In this study, out of 42 isolates, maximum congo red positive were from chicken $(72 \%)$ and human $(50 \%)$ followed by broiler (40\%) and goat $(40 \%)$.

In this study, all the isolates irrespective of the source of isolation were moderate to strong biofilm producers. Earlier several researchers have demonstrated in vitro biofilm-forming ability of $E$. coli isolates from various sources (Dewanti and Wong, 1995; Pratt and Kolter, 1998; Sheikh et al., 2001). However, in vitro biofilm-forming ability varies greatly among the E. coli isolates (Reisner et al., 2006). Sleytr et al. (1993) documented the prevalence of biofilm production among $17 \%$ faecal $E$. coli, $43 \%$ for cystitis, $40 \%$ for pyelonephritis and $42 \%$ for bacteraemic E. coli. Shetty et al. (2014) reported $20 \%$ of the intestinal commensal $E$. coli to be biofilm formers.

Proteases play a crucial role in virulence which helps in the survival and immune evasion of the pathogen (Iqbal et al., 2013). Several researchers have demonstrated the proteolytic activity of $E$. coli (Haddadi et al., 2005; Budiarti and Mubarik, 2007; Abed et al., 2016). In this study, we have also observed high proteolytic activity of $E$. coli isolates irrespective of the source of isolation. Earlier researchers have demonstrated high hemolysin producing ability of $E$. coli from various sources (Johnson, 1991; Mandal et al., 2001; Raksha et al., 2003; Sharma et al., 2007; Fakruddin et al., 2013; Shetty et al., 2014). Raksha et al. (2003) reported a high percentage (41\%) of haemolytic E. coli from urinary samples. Likewise, Shetty et al. (2014) reported $28.66 \%$ and $15 \%$ of extra-intestinal and intestinal commensal E. coli isolates to be hemolysin producer, respectively. Haemolytic activity is often associated with pathogencity of $E$. coli (Johnson, 1991). E. coli strains mostly produce $\alpha$-haemolysin (Shetty et al., 2014; Bhrugubalda et al., 2016), which possibly contributes to the virulence since it conferred virulence to nonpathogenic E. coli strains (Elliott et al., 1998). There is an existing correlation between the hemagglutinating ability and adhesiveness of several enteric pathogens (Qadri et al., 1994). Further, the receptors on the erythrocytes vary from species to species and the haemagglutination activity of $E$. coli isolates could indicate a clue as to the nature of the receptors for these pathogens in the intestinal mucosa (Hagberg et al., 1981; Qadri et al., 
1994). All the isolates were haemolysin producer with very strong haemolysin titre, which may pose a potential threat to these species.

Antibiotic resistance among the $E$. coli is rapidly increasing due to indiscriminate use of antibiotics (Bhrugubalda et al., 2016). Earlier, the multidrug-resistance pattern of $E$. coli strains against ampicillin, ciprofloxacin, gentamycin, sulfamethoxazole, and tetracycline has been reported (Mohammadi-Sardo et al., 2017). Besides, studies have also indicated a significant correlation between multidrug resistance pattern, biofilm formation, and pathogenesis of $E$. coli (Ponnusamy et al., 2012; Poursina et al., 2018). Karigoudar et al. (2019) found that 90.6, 71.9, $65.6,59.3,56.3,56.3,53.1$ and $50.0 \%$ of biofilm-producing $\quad E$. coli were resistant towards erythromycin, amikacin, cotrimoxazole, ampicillin, meropenem, chloramphenicol, tobramycin, and gentamicin, respectively. In this study, $E$. coli isolates were found to be resistant to at least 5 tested antibiotics except for isolates from human stool samples. The high antibiotic resistance pattern was recorded from the isolates from fish, goat and broiler. Although the exact source of such antibiotics resistant strains in the GI tract of these animals needs thorough studies, their occurrence as normal autochthonous gut microbiota of these animals could be harmful to the host especially under stressful conditions

Extended-spectrum $\beta$-lactamases (ESBLs) are enzymes that mediate resistance to extended-

\section{REFERENCES}

Abed BK, Authman SH and Yassein KH, 2016. Optimization of extracellular protease extracted from Escherichia coli. European J Pharm Med Res, 3(2): 113-118

Abd Samad NS, Amid A, Jimat DN and Shukor NA, 2017. Isolation and identification of halophilic bacteria producing halotolerant protease. Sci Herit J, 1: 07-09, doi: 10.26480/ gws.01.2017.07.09

Bauer AW, Kirby WM, Sherris JC and Turck M, 1966. spectrum cephalosporins, such as cefotaxime, ceftriaxone, and ceftazidime, and the monobactam aztreonam (Tenover et al., 1999). While some researchers observed a low rate of ESBL production by E. coli (Bhrugubalda et al., 2016), others reported a high rate of ESBL production by $E$. coli (Sharma et al., 2007). In this study, E. coli isolates from goat, pig and chicken were found to be ESBL producers. The findings of the present study agree with the views that the virulence of an organism may not be accurately predicted based on its measurable virulence factor phenotype but the presence of multiple virulence factors does increase the virulence of organisms (Bhrugubalda et al., 2016).

Therefore the present investigation showed that the normal gastrointestinal E. coli possess several virulent traits like biofilm-producing, congo red binding, proteolytic and haemolytic, which could be a predisposing factor for the onset of diseases in animals. Nonetheless, the ESBL positive along with the multidrug resistance pattern is a major concern since the possibility of horizontal transfer and possible health implications in the host as well as to human can't be ruled out.

Conflict of interest: The authors declare that they have no competing interests.

\section{ACKNOWLEDGEMENT}

The authors are thankful to the Head of the Department for providing necessary facility to carry out the present study.

Antibiotic susceptibility testing by a standardized single disc method. Am J Clin Pathol, 45(4): 493-496

Berkhoff HA and Vinal AC, 1986. Congo red medium to distinguish between invasive and non invasive Escherichia coli pathogenic for poultry. Avian Dis, 30(1): 117-121, doi: $10.2307 / 1590621$

Bhrugubalda A, Uma P, Yarlagadda P and Myeneni $\mathrm{RB}, 2016$. A study of virulence factors and drug resistance pattern in Escherichia coli isolated 
from extra intestinal infections in a tertiary care teaching hospital, Chinakakani, Guntur, Andhra Pradesh, South India. Int J Curr Microbiol App Sci, 5: 140-158, doi: 10.20546/ IJCMAS.2016.504.019

Budiarti S and Mubarik NR, 2007. Extracellular protease activity of enteropathogenic Escherechia coli on mucin substrate. Hayati J Biosci, 14: 36-38, doi:10.4308/hjb.14.1.36

Bryce A, Hay AD, Lane IF, Thornton HV, Wootton M et al., 2016. Global prevalence of antibiotic resistance in paediatric urinary tract infections caused by Escherichia coli and association with routine use of antibiotics in primary care: systematic review and meta-analysis. BMJ, 352: i939, doi: 10.1136/bmj.i939

Christensen GD, Simpson WA, Younger JJ, Baddour LM, Barrett FF et al., 1985. Adherence of coagulase-negative Staphylococci to plastic tissue culture plates: A quantitative model for the adherence of Staphylococci to medical devices. J Clin Microbiol, 22(6): 996-1006, doi: 10.1128/JCM.22.6.996-1006.1985

Clinical and Laboratory Standards Institute, 2014. Performance standards for antimicrobial susceptibility testing; twenty fourth informational supplement. CLSI document M100- S24, Clinical and Laboratory Standards Institute, Wayne, PA, USA

Cowan ST and Steel K, 1975. Manual for the identification of medical bacteria. $1^{\text {st }}$ edn., Cambridge University Press, Cambridge, USA

Cruickshank R, Dugwid TP, Marrimon BP and Swain RHH, 1975. Medical microbiology, $12^{\text {th }}$ edn. The English language Book Society, Churchil livingstone, London, pp806-821

de Mello Santos AC, Santos FF, Silva RM and Gomes TA, 2020. Diversity of hybrid-and heteropathogenic Escherichia coli and their potential implication in more severe diseases. Front Cell Infect Microbiol, 10: 339, doi: 10.3389/ fcimb.2020.00339

Dewanti R and Wong AC, 1995. Influence of culture conditions on biofilm formation by Escherichia coli O157:H7. Int J Food Microbiol, 26(2): 147 164, doi: 10.1016/0168-1605(94)00103-d

Elliott SJ, Srinivas S, Albert MJ, Alam K, Robins-
Browne RM et al., 1998. Characterization of the roles of hemolysin and other toxins in enteropathy caused by alpha-hemolytic Escherichia coli linked to human diarrhea. Infect Immunol, 66(5): 2040-2051, doi: 10.1128/IAI.66.5.2040-2051.1998

Fakruddin M, Mazumdar RM, Chowdhury A and Mannan KB, 2013. A preliminary study on virulence factors and antimicrobial resistance in extra intestinal pathogenic Escherichia coli (ExPEC) in Bangladesh. Indian J Med Res, 137(5): 988-990

Haddadi K, Moussaoui F, Hebia I, Laurent F and Roux YL, 2005. E. coli proteolytic activity in milk and casein breakdown. Reprod Nutr Dev, 45(4): 485-496, doi: 10.1051/rnd:2005033

Hagberg L, Jodal U, Korhonen TK, Lidin-Janson G, Lindberg $\mathrm{U}$ et al., 1981. Adhesion, hemagglutination, and virulence of Escherichia coli causing urinary tract infections. Infect Immu, 31(2): 564-570

Iqbal J, Rajani M, Siddiqui R and Khan NA, 2013. Neuropathogenic Escherichia coli K1 does not exhibit proteolytic activities to exert its pathogenicity. J Negat Results Biomed, 12: 8, doi: $10.1186 / 1477-5751-12-8$

Jafari A, Aslani MM and Bouzari S, 2012. Escherichia coli: A brief review of diarrheagenic pathotypes and their role in diarrheal diseases in Iran. Iran J Microbiol, 4(3): 102-117

Johnson JR, 1991. Virulence factors in Escherichia coli urinary tract infection. Clin Microbiol Rev, 4(1): 80 -128, doi: $10.1128 / \mathrm{cmr} \cdot 4.1 .80$

Karigoudar RM, Karigoudar MH, Wavare SM and Mangalgi SS, 2019. Detection of biofilm among uropathogenic Escherichia coli and its correlation with antibiotic resistance pattern. J Lab physicians, 11(1): 17, doi: 10.4103/ JLP.JLP_98_18

Mandal P, Kapil A, Goswami K, Das B and Dwivedi SN, 2001. Uropathogenic Escherichia coli causing urinary tract infection. Indian $\mathrm{J}$ Med Res, 114: 207-211

Mathur P, Kail A, Das B and Dhawan B, 2002. Prevalence of ESBL producing gram negative bacteria in a tertiary care hospital. Indian J Med Res, 115: 153-157 
Mohammadi-Sardo MR, Salehi S, Mirbaha S and Abdollahi A, 2017. Shiga toxigenic Escherichia coli antimicrobial resistance properties in diabetic and nondiabetic pediatric patients; a case-control study. Inter J Pediat, 5(11): 59996008, doi: 10.22038/ijp.2017.25624.2181

Odongo I, Ssemambo R and Kungu JM, 2020. Prevalence of Escherichia coli and its antimicrobial susceptibility profiles among patients with UTI at Mulago Hospital, Kampala, Uganda. Interdiscip Perspect Infect Dis, 2020: 8042540, doi: 10.1155/2020/8042540

Panigrahy B and Yushen L, 1990. Differentiation of pathogenic and non pathogenic Escherichia coli isolated from poultry. Avian Dis, 34(4): 941-943

Ponnusamy P, Natarajan V and Sevanan M, 2012. In vitro biofilm formation by uropathogenic Escherichia coli and their antimicrobial susceptibility pattern. Asian Pac J Trop Med, 5(3): 210-213, doi: 10.1016/S19957645(12)60026-1

Poursina F, Sepehrpour S and Mobasherizadeh S, 2018. Biofilm formation in nonmultidrug-resistant Escherichia coli isolated from patients with urinary tract infection in Isfahan, Iran. Adv Biomed Res, 7:40, doi: 10.4103/ abr.abr_116_17

Pratt LA and Kolter R, 1998. Genetic analysis of Escherichia coli biofilm formation: roles of flagella, motility, chemotaxis and type I pili. Mol Microbiol, 30(2): 285-293, doi: 10.1046/ j.1365-2958.1998.01061.x

Qadri F, Haque A, Faruque SM, Bettelheim KA, RobinsBrowne $\mathrm{R}$ et al., 1994. Hemagglutinating properties of enteroaggregative Escherichia coli. J Clin Microbiol, 32(2): 510-514

Raksha R, Srinivasa H and Macaden RS, 2003. Occurrence and characterization of uropathogenic Escherichia coli in urinary tract infections. Indian J Med Microbiol, 21(2): 102-107

Rawat D and Nair D, 2010. Extended-spectrum $\beta$ lactamases in Gram negative bacteria. J Glob Infect Dis, 2: 263-274, doi: 10.4103/0974$777 \mathrm{X} .68531$

Reisner A, Ho“ller BM, Molin S and Zechner EL, 2006.
Synergistic effects in mixed Escherichia coli biofilms: conjugative plasmid transfer drives biofilm expansion. J Bacteriol, 188(10): 35823588, doi: 10.1128/JB.188.10.3582-3588.2006

Roy P, Purushothaman V, Koteeswaran A and Dhillon AS, 2006. Isolation, characterization, and antimicrobial drug resistance pattern of Escherichia coli isolated from Japanese quail and their environment. J Appl Poul Res, 15(3): 442-446, doi: 10.1093/japr/15.3.442

Sasikala G, Ramavath UR and Jalily QA, 2019. Antimicrobial resistance pattern in Escherichia coli causing urinary tract infection among inpatients - A retrospective study. Int J Curr Microbiol App Sci, 8(7): 2198-2206, doi: 10.20546/ijcmas.2019.807.267

Sharma S, Bhat GK and Shenoy S, 2007. Virulence factors and drug resistance in Escherichia coli isolated from extraintestinal infections . Indian J Med Microbiol, 25(4): 369-373, doi: 10.4103/0255-0857.37341

Sheikh J, Hicks S, Dall'Agnol M, Phillips AD and Nataro JP, 2001. Roles for Fis and YafK in biofilm formation by enteroaggregative Escherichia coli. Mol Microbiol, 41(5): 983997, doi: 10.1046/j.1365-2958.2001.02512.x

Shetty SK, Rao SP, Subbannayya K and Janakiram K, 2014. Study of prevalence of virulence factors in extraintestinal pathogenic Escherichia coli isolated from a tertiary care hospital. Int J Curr Microbiol App Sci, 3(7): 1055-1061

Sleytr UB, Messner P, Pum D and Sára M, 1993. Crystalline bacterial cell surface layers. Mol Microbiol, 10(5): 911-916, doi: 10.1111/j.13652958.1993.tb00962.x

Tenover FC, Mohammed MJ, Gorton TS and Dembek ZF, 1999. Detection and reporting of organisms producing extended-spectrum beta-lactamases: survey of laboratories in Connecticut. J Clin Microbiol, 37(12): 4065-4070, doi: 10.1128/ jcm.37.12.4065-4070.1999

Thomson KS and Moland ES, 2000. Version 2000: The new $\beta$-lactamases of Gram-negative bacteria at the dawn of the new millennium. Microbes Infect, 2(10): 1225-1235, doi: 10.1016/s12864579(00)01276-4 